\title{
Nipple-Areola Complex Sensation after Nipple-sparing Mastectomy
}

\author{
Prakasit Chirappapha, MD \\ Pongsakorn Srichan, MD \\ Panuwat Lertsithichai, MD, PhD \\ Panya Thaweepworadej, MD \\ Thongchai Sukarayothin, MD \\ Monchai Leesombatpaiboon, MD \\ Youwanush Kongdan, MD
}

Background: Nipple-sparing mastectomy (NSM) has been proven to be oncologically safe for treating breast cancer. This procedure had been developed to optimize the esthetic outcome and reduce feeling mutilation after mastectomy. Risks of necrotic complications and diminishing nipple-areola complex (NAC) sensation are common complications affecting the patient's satisfaction after the surgery. The evaluation of NAC sensation should be also investigated.

Methods: We prospectively analyzed 55 NSMs that were performed on 52 patients for both therapeutic and prophylactic indications in Ramathibodi Hospital from May 2007 to September 2015. Patients' demographics, operative details, oncologic outcome, and postoperative complications, focusing on NAC sensation and necrotic complications, were analyzed.

Results: Forty-seven NSMs $(87 \%)$ were performed for therapeutic indications, and another 7 NSMs (13\%) were risk-reducing operations. Of the 43 patients performing NSM for breast cancer treatment, 33 patients $(77 \%)$ had invasive cancer and 11 patients $(23 \%)$ had ductal carcinoma in situ. One subareola base tissue was found an occult cancer, and the NAC was then removed. There were 3 locoregional recurrences after a median follow-up time of 24 months (range, 2-104 months). The NAC sensation was evaluated in a total of 35 patients. Twenty-five patients $(46 \%)$ underwent serial evaluation after 6 months of operation, and 10 patients were evaluated at more than 1 year after operation. In the first 6 months, 11 patients $(44 \%)$ showed partial sensation recovery, and 3 more patients had partial recovery after 1-year follow-up. Only 1 patient (2\%) had complete sensation recovery in all area of the NAC. In late evaluation group, 7 out of 10 patients had partial recovery. Most pain sensation remained in the lower aspect of the areola away from surgical incision.

Conclusions: NSM is technically feasible in selected patients with low rates of NAC removal. Some patients can preserve the NAC sensation. Long-term outcome should receive follow-up. (Plast Reconstr Surg Glob Open 2018;6:e1716; doi: 10.1097/ GOX.0000000000001716; Published online 19 April 2018.)

\section{BACKGROUND}

Nipple-areola complex (NAC) is a signature of the breast. Preservation of the NAC has a positive impact on patients' satisfaction with cosmetic results and feeling of mutilation. ${ }^{1}$ Nowadays, there are still no reconstruction techniques quite as satisfying as the real NAC. Nipplesparing mastectomy (NSM) is developed to optimize es-

From the Breast and Endocrine Surgery Unit, Department of surgery, Faculty of Medicine, Ramathibodi Hospital, Mahidol University, Bangkok, Thailand.

Received for publication August 29, 2017; accepted January 24, 2018.

Copyright @ 2018 The Authors. Published by Wolters Kluwer Health, Inc. on behalf of The American Society of Plastic Surgeons. This is an open-access article distributed under the terms of the Creative Commons Attribution-Non Commercial-No Derivatives License 4.0 (CCBY-NC-ND), where it is permissible to download and share the work provided it is properly cited. The work cannot be changed in any way or used commercially without permission from the journal. DOI: 10.1097/GOX.0000000000001716 thetic outcomes. However, the oncologic safety and the postoperative viability of the NAC are important concerns. Welling and Jensen ${ }^{2}$ postulated that the origin and progression of ductal carcinoma in the breast are from terminal duct lobular unit, and pathological study found only $9 \%$ of terminal duct lobular unit at the base of the nipple from mastectomy specimens. ${ }^{3}$ According to the aforementioned data, preservation of NAC can still be performed if there is no evidence of cancer cell at the base of the nipple. NSM is also an option for patients requiring riskreduction mastectomy and has a role in treating breast cancer in selected patients. ${ }^{4}$

Several studies reported an occult NAC involvement on mastectomy specimens varying from $0 \%$ to $58 \%$. These results are due to the differences in the inclusion criteria and the pathological assessment method between stud-

Disclosure: The authors have no financial interest to declare in relation to the content of this article. The Article Processing Charge was paid for by the authors. 
ies. ${ }^{4-6}$ Locoregional recurrence after NSM in both prophylactic and therapeutic settings ranged from $0 \%$ to $8.5 \% .^{5}$ Gerber et $\mathrm{al}^{7}$ reported $11.7 \%$ of local recurrence after performing NSM, which is comparable with $10.4 \%$ after skin-sparing mastectomy and $11.5 \%$ in modified radical mastectomy. Petit et $\mathrm{al}^{8}$ reported that 1,001 patients who performed NSM with the electron intraoperative treatment (ELIOT) had a local recurrence of $1.4 \%$, and all recurrences are observed outside NAC. De Alcantara et $\mathrm{al}^{9}$ updated an experience of NSM in Memorial Sloan Kettering Cancer Center. They reported no local recurrence, and only 1 patient had distant metastasis. Nowadays, there are still no prospective randomized controlled trials for evaluating the oncologic safety of NSM compared with the standard mastectomy.

The rate of nipple necrosis that ranged from $2 \%$ to $20 \%$ and nipple sensitivity following NSM reported from previous studies also markedly diminished. ${ }^{5}$ Yueh et a $1^{10}$ reported $75 \%$ preservation of the nipple sensation after NSM. These sensations are rated on a scale of 1-10 with a mean score of 3.0. Petit et $\mathrm{al}^{8}$ reported partial sensitivity of the NAC recovery in $15 \%$ of the patients with a mean score of 2/10. Another report from Wagner et $\mathrm{al}^{11}$ showed nipple sensation in terms of response time to erection, which prolonged at 6 months and remain constant at 1 year after surgery. Our study attempted to prospectively evaluate NAC viability, sensation, and also oncologic outcome of patients who underwent NSM.

\section{PATIENTS AND METHODS}

From January 2014 to July 2015, 52 patients underwent 55 NSMs for therapeutic or prophylactic indications in Breast and Endocrinology Unit of Ramathibodi Hospital. Preoperative evaluation included clinical examination, digital mammography, and breast ultrasound. Breast magnetic resonance imaging was not used routinely in our institution. Informed consent was obtained from all patients. The inclusion criteria were as follows: primary tumor located outside the areola, absence of nipple retraction or bloody nipple discharge, and absence of microcalcification at retroareolar. Multicentric/multifocal lesions that were distant from areola were included. Any preoperative chemotherapy or radiotherapy was not excluded from the study. Patients with inflammatory breast cancer and Paget's disease were excluded. Retroareolar soft tissue examination was performed in all patients. The NAC must be excised if positive tissue pathology was found, and the patient will be excluded from the study. Surgeons from our Breast and Endocrinology unit performed all procedures. This study received approval from the institutional review board of Ramathibodi Hospital, Mahidol University. A patient selection and the study design were shown in Figure 1.

\section{Operative Technique}

The skin incision for NSM includes the superolateral radial, superior circumareolar, lateral circumareolar, periareolar, omega incision, and others (design to incorporate prior breast surgical scar). The superolateral radial

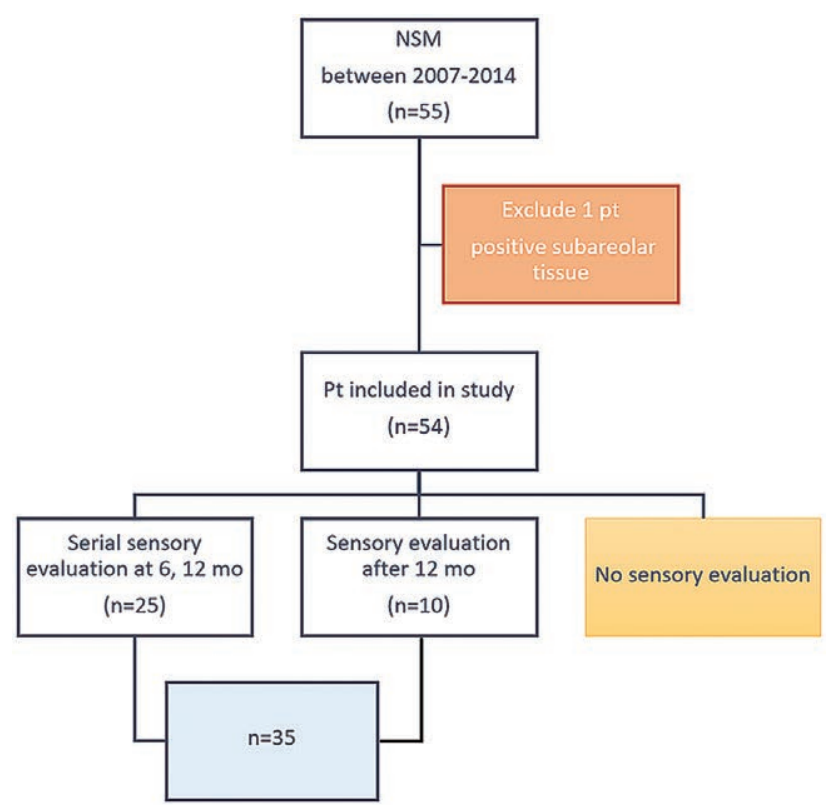

Fig. 1. Patient selection and study design.

incision was preferable, as it has a low risk of NAC necrosis and it facilitates access to axilla. The glandular breast tissue was dissected close to the dermis, leaving a thin subcutaneous layer of 3-5 $\mathrm{mm}$ to preserved subdermal vessels and dissected down to the pectoralis fascia. Dissection under the NAC was performed carefully. The glandular tissue and all ducts were coring out. The retroareolar tissue was removed separately and sent for frozen section examination (Fig. 2). If the frozen section result was positive, the NAC needs to be removed as mentioned above. The patients underwent immediate reconstruction with implants, autologous myocutaneous flap, or the combination of both.

The decision for adjuvant treatments depended on the multidisciplinary team. All patients were followed-up within 1 month after operation, then every 3 months for 2 years, and 6 months for 5 years to evaluate the operative and oncologic outcomes.

The NAC sensation was evaluated by pinprick sensation test (Fig. 3). Pointed stick was used to test the area of the nipple and the 4 quadrants around the areolar postoperatively at 6 and 12 months. Patients who performed NSM for more than 1 year were evaluated separately. The sensation was rated on scale of 0,1 , and 2 , representing no sensation, dull aching, and sharp pain, respectively. Partial sensation recovery was defined as any recovery of pinprick sensation in at least 1 quadrant of areolar or nipple. Full recovery was defined as the presenting of sharp sensation in all areas of NAC.

\section{Statistical Analysis}

Descriptive statistics were used to describe the demographic data, tumor characteristics, complications, and NAC sensation. Means, SDs, and ranges were used for continuous variables, whereas frequencies and percentages demonstrated categorical variables. 

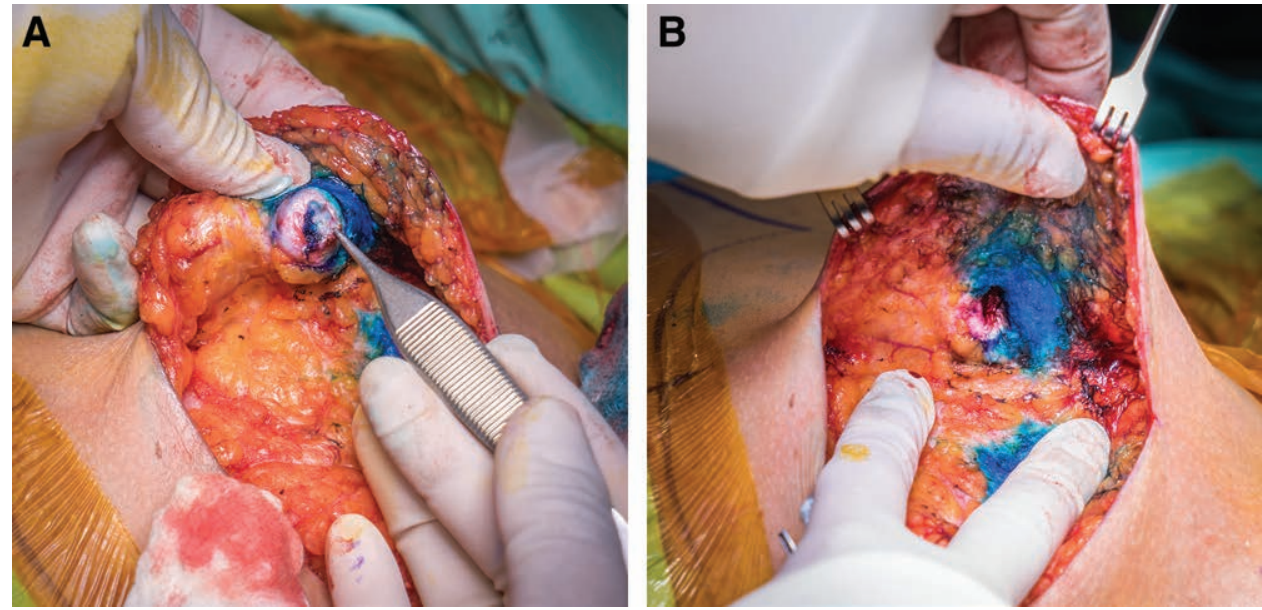

Fig. 2. The retroareolar glandular tissue was coring out. A, Retroareolar tissue was sent for frozen section. B, After core out the retroareolar tissue.

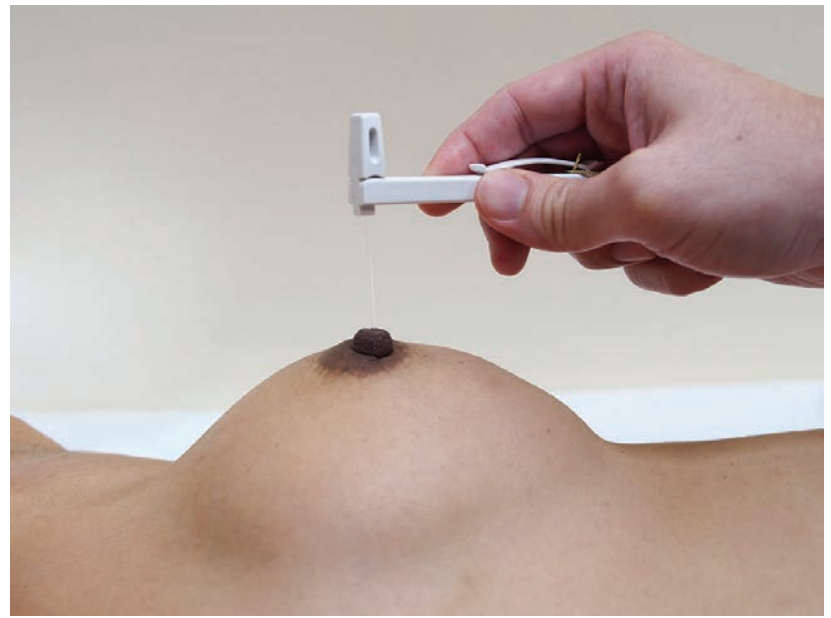

Fig. 3. Pinprick sensation test was performed by pointed stick around area of nipple and four quadrants of areolar.

\section{RESULTS}

Fifty-two women underwent 55 NSMs between January 2007 and December 2014. Subareola margin was positive for malignant cell in 1 patient $(0.02 \%)$, and thus this patient was excluded from the study. The indications for surgery were $48(87 \%)$ therapeutic and $7(13 \%)$ were prophylactic risk reduction. Thirty-three NSMs $(75 \%)$ were performed for breast cancer treatment. The mean age of patients was 43 years (31-59 years). The median distance of the nippletumor was $2.6 \mathrm{~cm}(0.5-7.8 \mathrm{~cm})$. The median follow-up period was 24 months (2-104 months) after the surgery. All patient characteristics data were shown in Table 1.

In 43 NSMs documented malignancy, $33(77 \%)$ were invasive cancer and another $10(23 \%)$ were ductal carcinoma in situ. The median tumor size was $2.5 \mathrm{~cm}(0.1-18 \mathrm{~cm})$. Seven NSMs (16\%) were multifocal cancer. Axillary lymph nodes metastasis was found in $15(35 \%)$. The intrinsic tumor subtypes are luminal A in 6 patients (18\%), luminal B in $16(48 \%)$, human epidermal growth factor receptor 2 (HER2) overexpression in $2(6 \%)$, and triple negative in 6 patients $(18 \%)$, respectively. Only 6 patients $(18 \%)$
Table 1. Baseline Characteristics of 54 Patients Underwent NSM from January 2014 to July 2015

\begin{tabular}{lc}
\hline Characteristics & $\begin{array}{c}\text { N }(\%) \text { or Mean } / \text { Median } \\
\text { (Range) }\end{array}$ \\
\hline Age $(\mathrm{y})$, mean & $43(30-60)$ \\
BMI $\left(\mathrm{kg} / \mathrm{m}^{2}\right)$, mean & $23.1(16.3-43.8)$ \\
Family history of breast cancer & $12(22)$ \\
NAC diameter $(\mathrm{cm})$, median & $3.3(2.1-4.9)$ \\
Nipple-tumor distance $(\mathrm{cm})$, median & $2.63(0.53-7.82)$ \\
Preoperative diagnosis & $43(80)$ \\
$\quad$ Cancer & $11(20)$ \\
$\quad$ Noncancer & $47(87)$ \\
Indication for surgery $\quad 7(13)$ \\
$\quad$ Therapeutic \\
Prophylaxis
\end{tabular}

BMI, body mass index.

received postoperative radiotherapy. Details of the tumor pathological characteristics were shown in Table 2.

Postoperative complications and type of necrosis were shown in Table 3. Necrotic complication was the most common complication in our study. Nipple necrosis occurred in 11 patients (20\%), but only 3 patients developed full thickness necrosis with 2 of them requiring surgical debridement. Only one of them had nipple loss and required total NAC excision. Partial skin flap necrosis occurred in 12 NSMs (22\%) and was successfully managed. Infection and seroma were another common complication in our study, but most of them can be resolved by conservative treatment.

Three patients developed locoregional recurrence during the follow-up period. One of them had Paget's disease of nipple at 31 months after surgery, and required NAC excision. The second patient had axillary lymph nodes recurrent after 15 months postoperatively without lesion in the NAC. So, we performed axillary lymph nodes dissection and postoperative radiotherapy. The last patient had local recurrent on her ipsilateral breast and internal mammary lymph nodes after 15 months without any evidence of a distant metastasis. We performed mastectomy with excision of internal 
Table 2. Tumor Pathological Characteristics from 54 Patients Underwent NSM

\begin{tabular}{|c|c|}
\hline Tumor Characteristics & N (\%) or Median (Range) \\
\hline \multicolumn{2}{|l|}{ Histological diagnosis } \\
\hline Invasive cancer & $33(61)$ \\
\hline In situ cancer & $10(18)$ \\
\hline Benign phyllodes tumor & $3(6)$ \\
\hline Benign condition & $8(15)$ \\
\hline Tumor size $(\mathrm{cm})$ & $2.5(0.1-18)$ \\
\hline \multicolumn{2}{|c|}{$\mathrm{N}$ stage (invasive cancer) $(\mathrm{n}=33)$} \\
\hline No & $17(52)$ \\
\hline N1 & $10(30)$ \\
\hline N2 & $5(15)$ \\
\hline Unknown & $1(3)$ \\
\hline \multicolumn{2}{|l|}{ Staging $(n=43)$} \\
\hline 0 (in situ) & $10(23)$ \\
\hline I & $9(21)$ \\
\hline IIA & $11(26)$ \\
\hline IIB & $6(14)$ \\
\hline III & $6(14)$ \\
\hline Unknown & $1(2)$ \\
\hline \multicolumn{2}{|c|}{ Grading of invasive cancer $(n=33)$} \\
\hline I & $1(3)$ \\
\hline II & $16(48)$ \\
\hline III & $13(39)$ \\
\hline Unknown & $3(9)$ \\
\hline \multicolumn{2}{|c|}{$\begin{array}{l}\text { Lymphovascular invasion in invasive } \\
\text { cancer }(\mathrm{n}=33)\end{array}$} \\
\hline Yes & $6(18)$ \\
\hline No & $25(76)$ \\
\hline Unknown & $2(6)$ \\
\hline \multicolumn{2}{|l|}{ Multifocal cancer $(\mathrm{n}=33$ ) } \\
\hline Yes & $6(18)$ \\
\hline No & $25(76)$ \\
\hline Unknown & $2(6)$ \\
\hline \multicolumn{2}{|l|}{ Hormone status $(\mathrm{n}=33)$} \\
\hline ER or PR+ & $24(73)$ \\
\hline $\mathrm{ER} / \mathrm{PR}-$ & $8(24)$ \\
\hline Unknown & $1(3)$ \\
\hline \multicolumn{2}{|l|}{ HER2 expression $(\mathrm{n}=33)$} \\
\hline None & $21(64)$ \\
\hline Equivocal & $6(18)$ \\
\hline Positive & $6(18)$ \\
\hline \multicolumn{2}{|c|}{ Invasive tumor subtype $(\mathrm{n}=33)$} \\
\hline Luminal A & $6(18)$ \\
\hline Luminal B & $16(48)$ \\
\hline HER2 overexpression & $2(6)$ \\
\hline Triple negative & $6(18)$ \\
\hline Unknown & $3(9)$ \\
\hline
\end{tabular}

$\mathrm{ER}$ = estrogen receptor; $\mathrm{PR}=$ progesterone receptor; HER2 = human epidermal growth factor receptor 2

Table 3. Postoperative Complications after NSM in 54 Patients

\begin{tabular}{lc}
\hline Complications & N (\%) \\
\hline NAC necrosis & \\
$\quad$ Partial & $8(15)$ \\
Full thickness & $3(5)$ \\
Skin flap necrosis & \\
Partial & $12(22)$ \\
Full thickness & 0 \\
Other complications & $9(17)$ \\
$\quad$ Seroma & $10(18)$ \\
Infection & $6(11)$ \\
Fat necrosis & \\
\hline
\end{tabular}

mammary lymph nodes followed by postoperative radiotherapy.

The NAC sensation was evaluated in 25 NSMs (46.3\%) at 6 months after operation. One patient (4\%) had complete recovery of the NAC sensation. Another 11 patients
Table 4. Nipple-Areola Sensation and Sensation Score Evaluated from 35 Patients after NSM

\begin{tabular}{lc}
\hline NAC Sensation & N (\%) \\
\hline Incision type & \\
Superolateral radial & $17(49)$ \\
Others & $18(51)$ \\
Sensation at medial upper area of areola & $19(54)$ \\
No sensation & $12(34)$ \\
Dull sensation & $4(11)$ \\
Sharp sensation & $\mathbf{2 0}$ \\
Total sensation score & $20(57)$ \\
Sensation at lateral upper area of areola & $12(34)$ \\
No sensation & $3(9)$ \\
Dull sensation & $\mathbf{1 8}$ \\
Sharp sensation & $18(51)$ \\
Total sensation score & $13(37)$ \\
Sensation at medial lower area of areola & $4(11)$ \\
No sensation & $\mathbf{2 1}$ \\
Dull sensation & $19(54)$ \\
Sharp sensation & $14(40)$ \\
Total sensation score & $2(6)$ \\
Sensation at lateral lower area of areola & $\mathbf{1 8}$ \\
No sensation & \\
Dull sensation & $22(63)$ \\
Sharp sensation & $11(31)$ \\
Total sensation score & $1(3)$ \\
Sensation at nipple & $1(3)$ \\
No sensation & $\mathbf{1 3}$ \\
Dull sensation & \\
Sharp sensation & \\
Unknown & \\
Total sensation score & \\
\hline
\end{tabular}

(44\%) had partial sensation recovery, and 3 more patients had recovery after 1-year follow-up. Ten other patients who performed NSM over a year in this study were evaluated separately. Twenty-one of 35 patients $(60 \%)$ had partial recovery of NAC sensation. NSM was performed on 17 of them with superolateral radial incision, and most of the residual sensation remained in the lower aspect of the areola away from the surgical incision. (Fig. 4) The sensations of the areola and nipple area from all 35 patients were shown in Table 4. In Figure 5, we demonstrated late esthetic result after NSM in one of our patient.

\section{DISCUSSION}

In our series, 43 NSMs were performed mainly to treat breast cancer. NSM was technically feasible to perform in selected patients according to the inclusion criteria. The rate of NSM in our institute from the past was due to the extended indication from prophylactic setting for treating breast cancer. Some proponent argued about the oncologic safety of this procedure. In standard mastectomy, the NAC was excised with mastectomy specimen to eliminate the residual glandular tissue beneath the NAC. Several studies reported the rate of nipple involvement in mastectomy specimen ranging from $0 \%$ to $58 \% \%^{8,12-19}$ These conflict data reflect variation in the selected criteria, tissue processing, and histopathologic analysis. Brachtel et $\mathrm{al}^{19}$ found a correlation between the occult nipple tumor and the tumor at the retroareolar en face margin. For this reason, the NAC can be preserved if the intraoperative frozen section analysis of the retroareolar base tissue was free from carcinoma. One of 43 NSMs (2.3\%) from our study had carcinoma at the retroareolar margin 


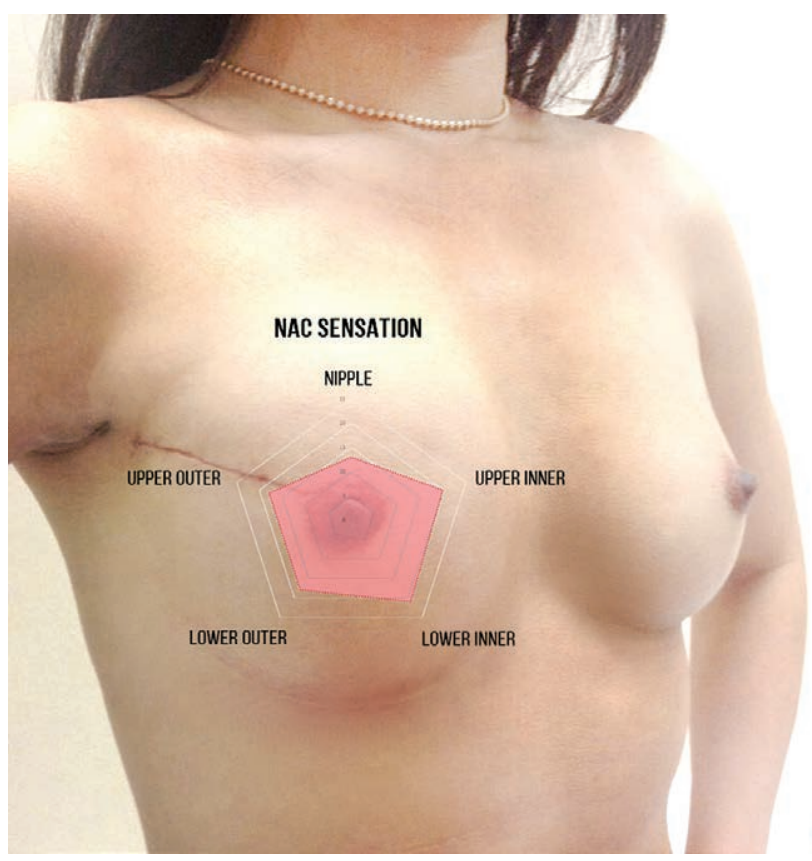

Fig. 4. The picture displays the diagram of sensation score together with the picture of skin incision.

on the final pathologic analysis, and the NAC was then removed. There were 3 locoregional recurrences $(7 \%)$ in our study, mostly on the regional lymph nodes. Only 1 patient who performed NSM to treat ductal carcinoma in situ had recurrence with Paget's disease on her nipple after 31 months. Several studies have shown that the local recurrence rate after NSM ranged from $0 \%$ to $8.5 \% \%^{7,8,20-23}$ with longer follow-up period. The major complications after NSM were the NAC and skin flap necrosis. Nipple necrosis rate from previous reports ranged from $2 \%$ to 20\%. ${ }^{24-28}$ Our study showed 3 patients $(5 \%)$ with full thickness necrosis of the NAC and $1.8 \%$ rate of NAC removal that was consistent with the result from previous literature. Although the rate of the partial NAC and skin flap necrosis was quite high ( $15 \%$ and $22 \%$, respectively), all of them can be successfully managed.

Nipple sensitivity following NSM was markedly diminished. Few studies have evaluated NAC sensation with various methods after NSM. Anatomical studies found that the anterior and lateral cutaneous branches of the third, fourth, or fifth intercostal nerve innervate the nipple and the areola..$^{29}$ Nerves that supply the nipple pass through the gland to the posterior surface of the nipple and therefore will most likely be injured when we performed resection of retroareolar tissue for frozen section. Yueh et a ${ }^{10}$ reported postoperative sensitivity results on 17 NSMs that showed $75 \%$ preserving of NAC sensation. ${ }^{10}$ In contrast, Petit et al ${ }^{8}$ reported a partial sensitivity of the NAC recovery in $15 \%$ of patients. ${ }^{8}$ We performed pinprick sensation test in the nipple and areola area on 35 patients and found partial recovery of NAC sensation in $60 \%$. Most residual sensation remains in the lower aspect of the areola away from the surgical incision. One patient $(2.8 \%)$ who underwent mastectomy to treat phyllodes tumor for more thickness of skin

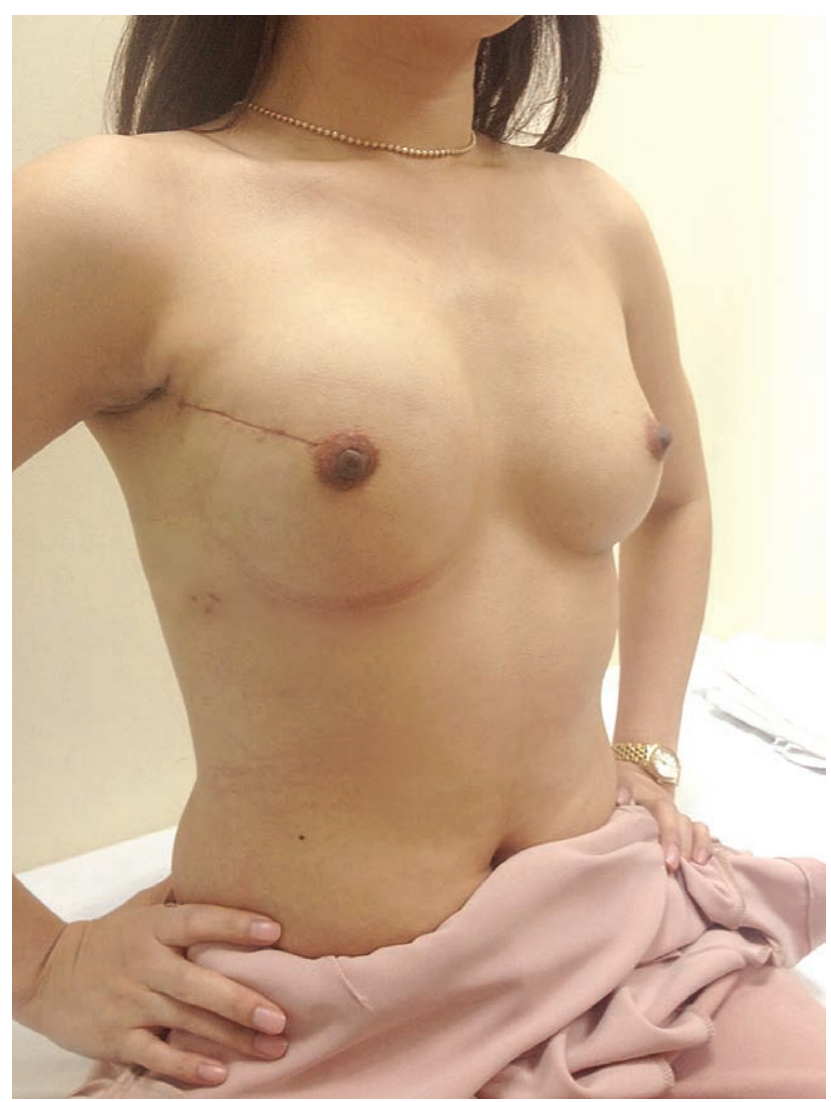

Fig. 5. Six months postoperative result from the patient after performing nipple-sparing mastectomy on her right breast.

flap without a retroareolar tissue resection had complete recovery of NAC sensation. The limitation of this study was the small sample size and the short follow-up time. We cannot analyze the factors that correlate with local recurrence, NAC necrosis, or NAC sensation.

In summary, this study demonstrated the feasibility to perform NSM in selected patients, with a low risk of NAC removal and local recurrence rate. NAC sensation can be preserved in some patients in the area far beyond the skin incision.

Panuwat Lertsithichai, $\mathbf{M D}, \mathbf{P h D}$
Breast and Endocrine Surgery Unit
Department of Surgery
Faculty of Medicine
Ramathibodi Hospital
Mahidol University
Bangkok 10400, Thailand
E-mail: panuwat.ler@mahidol.ac.th

\section{ACKNOWLEDGMENTS}

We thank Ms. Nichakarn Kuphirun for English revision of the text.

\section{REFERENCES}

1. Didier F, Radice D, Gandini S, et al. Does nipple preservation in mastectomy improve satisfaction with cosmetic results, psychological adjustment, body image and sexuality? Breast Cancer Res Treat. 2009;118:623-633. 
2. Wellings SR, Jensen HM. On the origin and progression of ductal carcinoma in the human breast. J Natl Cancer Inst. 1973;50:11111118.

3. Stolier AJ, Wang J. Terminal duct lobular units are scarce in the nipple: implications for prophylactic nipple-sparing mastectomy: terminal duct lobular units in the nipple. Ann Surg Oncol. 2008; 15:438-442.

4. Rusby JE, Smith BL, Gui GP. Nipple-sparing mastectomy. $\mathrm{Br} J$ Surg. 2010;97:305-316.

5. Murthy V, Chamberlain RS. Nipple-sparing mastectomy in modern breast practice. Clin Anat. 2013;26:56-65.

6. Laronga C, Smith P. Nipple-sparing mastectomy: an oncologic and cosmetic perspective. Surg Oncol Clin N Am. 2014;23:549566.

7. Gerber B, Krause A, Dieterich M, et al. The oncological safety of skin sparing mastectomy with conservation of the nipple-areola complex and autologous reconstruction: an extended follow-up study. Ann Surg. 2009;249:461-468.

8. Petit JY, Veronesi U, Orecchia R, et al. Nipple sparing mastectomy with nipple areola intraoperative radiotherapy: one thousand and one cases of a five years experience at the European institute of oncology of Milan (EIO). Breast Cancer Res Treat. 2009;117:333-338.

9. de Alcantara Filho P, Capko D, Barry JM, et al. Nipple-sparing mastectomy for breast cancer and risk-reducing surgery: the Memorial Sloan-Kettering Cancer Center experience. Ann Surg Oncol. 2011;18:3117-3122.

10. Yueh JH, Houlihan MJ, Slavin SA, et al. Nipple-sparing mastectomy: evaluation of patient satisfaction, aesthetic results, and sensation. Ann Plast Surg. 2009;62:586-590.

11. Wagner JL, Fearmonti R, Hunt KK, et al. Prospective evaluation of the nipple-areola complex sparing mastectomy for risk reduction and for early-stage breast cancer. Ann Surg Oncol. 2012;19:1137-1144.

12. Morimoto T, Komaki K, Inui K, et al. Involvement of nipple and areola in early breast cancer. Cancer. 1985;55:2459-2463.

13. Lüttges J, Kalbfleisch H, Prinz P. Nipple involvement and multicentricity in breast cancer. A study on whole organ sections. $J$ Cancer Res Clin Oncol. 1987;113:481-487.

14. Menon RS, van Geel AN. Cancer of the breast with nipple involvement. BrJ Cancer. 1989;59:81-84.

15. Verma GR, Kumar A, Joshi K. Nipple involvement in peripheral breast carcinoma: a prospective study. Indian J Cancer. 1997;34:1-5
16. Vyas JJ, Chinoy RF, Vaidya JS. Prediction of nipple and areola involvement in breast cancer. Eur J Surg Oncol. 1998;24:15-16.

17. Laronga C, Kemp B, Johnston D, et al. The incidence of occult nipple-areola complex involvement in breast cancer patients receiving a skin-sparing mastectomy. Ann Surg Oncol. 1999;6:609613.

18. Simmons RM, Brennan M, Christos P, et al. Analysis of nipple/ areolar involvement with mastectomy: can the areola be preserved? Ann Surg Oncol. 2002;9:165-168.

19. Brachtel EF, Rusby JE, Michaelson JS, et al. Occult nipple involvement in breast cancer: clinicopathologic findings in 316 consecutive mastectomy specimens. J Clin Oncol. 2009;27:49484954.

20. Sacchini V, Pinotti JA, Barros AC, et al. Nipple-sparing mastectomy for breast cancer and risk reduction: oncologic or technical problem? J Am Coll Surg. 2006;203:704-714.

21. Voltura AM, Tsangaris TN, Rosson GD, et al. Nipple-sparing mastectomy: critical assessment of 51 procedures and implications for selection criteria. Ann Surg Oncol. 2008;15:3396-3401.

22. Benediktsson KP, Perbeck L. Survival in breast cancer after nipple-sparing subcutaneous mastectomy and immediate reconstruction with implants: a prospective trial with 13 years median follow-up in 216 patients. Eur J Surg Oncol. 2008;34:143-148.

23. Paepke S, Schmid R, Fleckner S, et al. Subcutaneous mastectomy with conservation of the nipple-areola skin: broadening the indications. Ann Surg. 2009;250:288-292.

24. Crowe JP Jr, Kim JA, Yetman R, et al. Nipple-sparing mastectomy: technique and results of 54 procedures. Arch Surg. 2004;139:148150 .

25. Komorowski AL, Zanini V, Regolo L, et al. Necrotic complications after nipple- and areola-sparing mastectomy. World J Surg. 2006;30:1410-1413.

26. Garwood ER, Moore D, Ewing C, et al. Total skin-sparing mastectomy: complications and local recurrence rates in 2 cohorts of patients. Ann Surg. 2009;249:26-32.

27. Spear SL, Willey SC, Feldman ED, et al. Nipple-sparing mastectomy for prophylactic and therapeutic indications. Plast Reconstr Surg. 2011;128:1005-1014.

28. Algaithy ZK, Petit JY, Lohsiriwat V, et al. Nipple sparing mastectomy: can we predict the factors predisposing to necrosis? Eur J Surg Oncol. 2012;38:125-129.

29. Schlenz I, Kuzbari R, Gruber H, et al. The sensitivity of the nipple-areola complex: an anatomic study. Plast Reconstr Surg. 2000;105:905-909. 